\title{
Cdc28-Clb5 (CDK-S) and Cdc7-Dbf4 (DDK) collaborate to initiate meiotic recombination in yeast
}

\author{
Lihong Wan, ${ }^{1}$ Hengyao Niu, ${ }^{1}$ Bruce Futcher, ${ }^{2}$ Chao Zhang, ${ }^{3}$ Kevan M. Shokat, ${ }^{3}$ Simon J. Boulton, ${ }^{4}$ \\ and Nancy $M$. Hollingsworth ${ }^{1,5}$ \\ ${ }^{1}$ Department of Biochemistry and Cell Biology, Stony Brook University, Stony Brook, New York 11794, USA; ${ }^{2}$ Department \\ of Molecular Genetics and Microbiology, Stony Brook University, Stony Brook, New York 11794, USA; ${ }^{3}$ Department of \\ Cellular and Molecular Pharmacology, University of California at San Francisco, San Francisco, California 94158, USA; \\ ${ }^{4}$ London Research Institute, Clare Hall Laboratories, South Mims, Herts EN6 3LD, United Kingdom
}

\begin{abstract}
S-phase cyclin-dependent kinase Cdc28-Clb5 (CDK-S) and Dbf4-dependent kinase Cdc7-Dbf4 (DDK) are highly conserved kinases well known for their roles in the initiation of DNA replication. CDK-S is also essential for initiation of meiotic recombination because it phosphorylates Ser30 of Mer2, a meiosis-specific double-strand break (DSB) protein. This work shows that the phosphorylation of Mer2 Ser30 by CDK-S primes Mer2 for subsequent phosphorylation by DDK on Ser29, creating a negatively charged "patch" necessary for DSB formation. CDK-S and DDK phosphorylation of Mer2 S30 and S29 can be bypassed by phosphomimetic amino acids, but break formation under these conditions is still dependent on DDK and CDK-S activity. Coordination between premeiotic $S$ and DSB formation may be achieved by using CDK-S and DDK to initiate both processes. Many other proteins important for replication, recombination, repair, and chromosome segregation contain combination DDK/CDK sites, raising the possibility that this is a common regulatory mechanism.
\end{abstract}

[Keywords: Meiotic recombination; Cdc7; double-strand breaks; CDK; phosphorylation]

Supplemental material is available at http://www.genesdev.org.

Received October 16, 2007; revised version accepted December 7, 2007.

Meiosis is a highly conserved, specialized form of cell division that creates haploid gametes from diploid cells by dividing the chromosome number in half. The reduction in chromosome number is highly specific, such that cells receive one copy of each chromosome, and is accomplished by two rounds of chromosome segregation following a single round of chromosome duplication. The first division, MI, is unique to meiosis. Pairs of homologous sister chromatids segregate to opposite poles, in contrast to mitosis, where sister chromatids separate. Proper MI segregation requires that homologous chromosomes be physically connected by a combination of crossing over and sister chromatid cohesion (for review, see Petronczki et al. 2003). In the absence of interhomolog crossovers, homologs segregate randomly at MI, producing chromosomally imbalanced gametes that are generally incapable of producing viable offspring.

Recombination is initiated during meiosis by doublestrand breaks (DSBs), catalyzed by a meiosis-specific, topoisomerase-like protein called Spo11. spo11 mutants in

${ }^{5}$ Corresponding author.

E-MAIL nhollin@ms.cc.sunysb.edu; FAX (631) 632-8575.

Article is online at http://www.genesdev.org/cgi/doi/10.1101/gad.1626408. a variety of species, including budding and fission yeasts, worms, plants, fruit flies, and mice are defective in recombination, illustrating the remarkable evolutionary conservation of this recombination mechanism (Keeney 2001). DSBs occur preferentially at specific sites in the genome called recombination "hot spots" (Petes 2001). In budding yeast, numerous genes in addition to SPO11 are required for DSB formation. These include Mre11/Rad50/Xrs2, part of the MRX complex also utilized for recombination in vegetative cells, as well as the meiosis-specific genes MER2/REC107, REC102, REC104, REC114, MEI4, and SKI8 (Pecina et al. 2002). Although recent work has described subcomplexes for some of these proteins (e.g., Rec102/Rec104/Spo11/Ski8 and Mer2/Mei4/Rec114), how these proteins work together to initiate DSB formation is still not understood (Jiao et al. 2003; Arora et al. 2004; Li et al. 2006; Maleki et al. 2007).

Failure to repair meiotic DSBs prior to chromosome segregation is disastrous for a cell. DSB formation and repair are therefore highly regulated processes. Recombination between homologs, rather than sister chromatids, is promoted both by use of a meiosis-specific RecA ortholog, Dmc1, and the suppression of sister chromatid 
repair mediated by Mek1/Mre4, a meiosis-specific kinase (Bishop et al. 1992; Schwacha and Kleckner 1997; Wan et al. 2004). In addition, DSB formation is coordinated with other meiotic events, such that DSBs occur after premeiotic DNA synthesis (Borde et al. 2000). Various checkpoints function during meiosis to prevent chromosome segregation at MI in mutant situations where DNA replication is incomplete or recombination intermediates fail to get processed (Hochwagen and Amon 2006). How replication and DSB formation are coordinated in wild-type cells is not yet understood. However, recent results have indicated that the S-phase cyclin-dependent kinase Cdc28-Clb5,6 (CDK-S) may be involved (Henderson et al. 2006).

CDK-S is a highly conserved, essential protein kinase required for DNA replication in both mitotic and meiotic cells (Stuart and Wittenberg 1998; Bell and Dutta 2002; Benjamin et al. 2003). In the absence of CDK-S activity, neither premeiotic DNA synthesis nor meiotic DSBs occur. Initially, this led to the suggestion that DNA synthesis is a prerequisite for DSB formation (Borde et al. 2000; Smith et al. 2001; Benjamin et al. 2003). Recently, however, Henderson et al. (2006) showed that CDK-S affects DSB formation directly, by phosphorylating Ser30 (S30) of Mer2. The mer2-S30A mutant fails to make DSBs, and consequently produces inviable spores. Mer2 physically interacts with Mei4 and Rec114 and mer2-S30A disrupts these interactions, suggesting that the function of CDK-S phosphorylation of Mer2 is to promote the formation of larger protein complexes essential for making DSBs (Henderson et al. 2006; $\mathrm{Li}$ et al. 2006). The fact that CDK-S kinase activity is also required for the initiation of premeiotic $S$ raises the possibility that these two processes may be linked by the action of this kinase.

Cdc7 is another conserved, essential kinase required for the initiation of DNA replication in mitotically dividing cells (Sclafani 2000; Masai and Arai 2002). Like CDK-S, Cdc7 kinase activity requires a catalytic subunit (Cdc7) that is present constitutively throughout the cell cycle, and a regulatory subunit (Dbf4), whose levels fluctuate (Nougarede et al. 2000). The Cdc7-Dbf4 complex is referred to as DDK, for Dbf4-dependent kinase. Genetic studies in budding yeast indicate that there is a sequential order to kinase action for replication, with CDK-S preceding DDK (Nougarede et al. 2000). It has been suggested that CDK-S phosphorylation of target proteins might prime subsequent DDK phosphorylation of the same protein on adjacent residues; for instance, in vitro studies show that DDK phosphorylation of $\mathrm{Mcm} 2$ is enhanced by prior CDK phosphorylation (Cho et al. 2006; Montagnoli et al. 2006). However, whether coordinated phosphorylation of replication proteins by CDK-S and DDK at specific sites is functionally relevant is not yet known.

Inactivation of DDK during meiosis using temperature sensitive alleles of $C D C 7\left(c d c 7^{t s}\right)$ has no effect on premeiotic DNA synthesis, but it does prevent recombination and causes a Prophase I arrest (Schild and Byers 1978; Hollingsworth and Sclafani 1993). However, these experiments cannot exclude a role for DDK in premeiotic $\mathrm{S}$, because the $\mathrm{Cdc} 7^{\mathrm{ts}}$ kinase may not have been completely inactivated at the restrictive temperature. Abolishing DDK function by repression of DBF4 transcription prior to entry into meiosis causes delays in premeiotic DNA replication, arguing for a role for DDK in this process (Valentin et al. 2005). As an alternative approach to inactivating DDK during meiosis, a conditional version of $C D C 7$ (cdc7-as) was created by enlarging the ATP-binding pocket of Cdc7, thereby creating a mutant kinase that can be inactivated by addition of purine analogs to the sporulation medium (Wan et al. 2006). This chemical genetic approach was previously successful in revealing an essential role for CDC28 in premeiotic DNA replication that was not detected using cdc28 $8^{t s}$ mutants (Shuster and Byers 1989; Benjamin et al. 2003). Similar to the DBF4 shutoff situation, $c d c 7$-as diploids induced to undergo meiosis in the presence of kinase inhibitor did successfully synthesize DNA, but with a delay (Wan et al. 2006). Like $c d c 7^{t s}$, inactivation of $c d c 7$-as prevents recombination and causes a prophase arrest. The lack of recombination is due to a lack of DSBs. When the kinase inhibitor is removed, DSBs rapidly appear and cells proceed synchronously through meiosis, indicating that the cells are arrested immediately prior to DSB formation (Wan et al. 2006). Here, we show that a critical target of DDK for DSB formation is Mer2, and that CDK-S and DDK function sequentially to phosphorylate Mer2 on the adjacent serines S30 and S29, allowing formation of meiotic DSBs.

\section{Results}

DDK activity is required for phosphorylation of the DSB protein Mer2

Inhibition of Cdc7-as (hereafter referred to as DDK-as) during meiosis prevents DSB formation and recombination and cells arrest prior to Meiosis I due to a lack of NDT80 transcription (Wan et al. 2006; Sasnuma et al. 2008; data not shown). Several DSB proteins were tested for gel mobility shifts that were dependent on DDK-as activity. No differences in mobility were observed for Mre11, Ski8, Rec102, or Cdc7 (data not shown). The mobility of Mer2, however, was increased when DDK-as was inactivated by the inhibitor PP1 [4-amino-1-tert-butyl-3-(p-methylphenyl) pyrazolo (3,4-d) pyrimidine] (Fig. 1A). Phosphatase experiments confirmed that the missing modification is phosphorylation (Fig. 1A). Inactivation of DDK-as reduces, but does not eliminate Mer2 phosphorylation. This could be because DDK-as is not fully inactivated under these conditions. Alternatively, the residual Mer2 phosphorylation could be due to CDK-S or another kinase (Fig. 1A). Similar conclusions were reached by Sasanuma et al. (2008).

If DDK-dependent phosphorylation of Mer2 is important for making DSBs, then Mer2 phosphorylation should occur prior to DSB formation. This prediction was tested by transferring $c d c 7$-as MER2-myc5 cells to Spo medium and adding $15 \mu \mathrm{M}$ PP1 to part of the culture. 

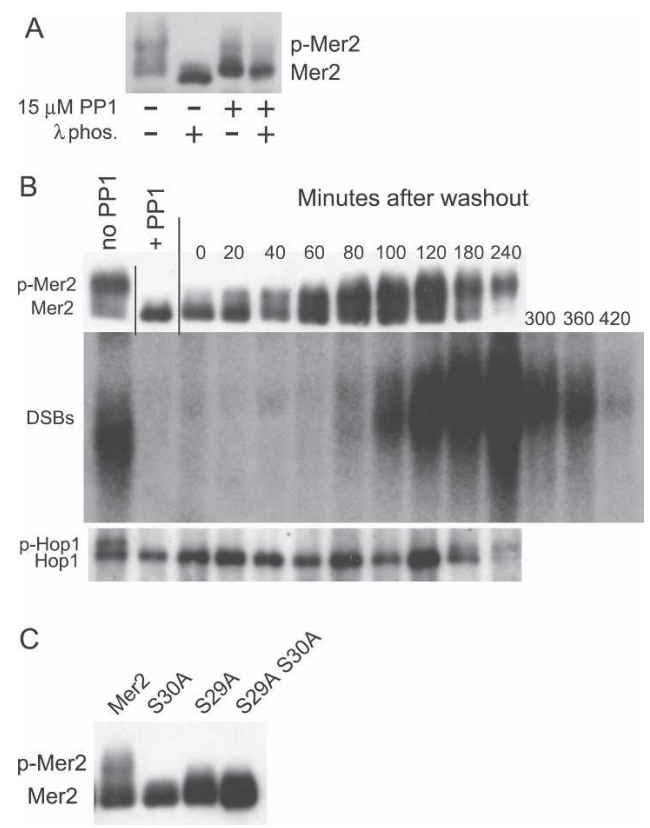

Figure 1. Effects on Mer2 phosphorylation of DDK-as inactivation and the S29A mutation. (A) A cdc7-as MER2-myc8 diploid (NH692) was sporulated in the absence $(-)$ or presence $(+)$ of $15 \mu \mathrm{M}$ PP1 for $8 \mathrm{~h}$ at $30^{\circ} \mathrm{C}$. Mer2-myc8 was immunoprecipitated and treated with $\lambda$ protein phosphatase as indicated. (B) A $c d c 7$ as MER2-myc5 diploid (NH780::pKH35) was transferred to 300 $\mathrm{mL}$ of Spo medium at $30^{\circ}$ and $15 \mu \mathrm{M}$ PP1 was added to $250 \mathrm{~mL}$. The remainder was sporulated without PP1. After 8 h, PP1 was washed out (wo) and the cells returned to $30^{\circ} \mathrm{C}$. Mer2 and Hop1 were immunoprecipitated at the indicated time points (up to 240 min after washout) and detected by immunoblot analysis using $\alpha$-myc and Hopl antibodies, respectively. DSBs were monitored at the YCR048w hot spot up to 420 min after washout (Wu and Lichten 1994). p-Mer2 and p-Hop1 indicate phosphorylated Mer2 and Hop1, respectively. (C) MER2-MYC5 (NH782::pKH35), mer2-S30A-myc5 (NH782::pKH36), mer2S29A-myc5 (NH782::pKH35-S29A), and mer2-S29A S30Amyc5 (NH782::pKH36-S29A) diploids were sporulated for $4 \mathrm{~h}$ at $30^{\circ} \mathrm{C}$, and Mer2 proteins were immunoprecipitated and detected on immunoblots using $\alpha$-myc antibodies.

After $8 \mathrm{~h}$ in Spo medium, cells without PP1 exhibited phosphorylated Mer2 and Hop1, as well as DSBs (Fig. 1B). In contrast, no DSBs, phospho-Hop1 or phosphoMer2 were detected in cells incubated with PP1. At $8 \mathrm{~h}$, the PP1 was washed out and the cells were resuspended in Spo medium and returned to the shaker (this time is defined as 0 min after washout). Some DDK-as molecules became active during the washout protocol (which takes $\sim 40 \mathrm{~min}$ ), as an increase in phospho-Mer2 was detectable at the 0 time point (Fig. 1B). Equal amounts of phosphorylated and unphosphorylated Mer2 were present within 60 min after washout, while DSBs were not detected until 80 min post-washout. PhosphoHopl was observed $2 \mathrm{~h}$ after DSBs were first detected (Fig. 1B). The temporal order of these events is therefore Mer2 phosphorylation, then DSB formation, then Hop1 phosphorylation.
Residues Ser29 and Ser30 of Mer2 are both required for the full phosphorylation mobility shift

Given that Mer2 phosphorylation is dependent on DDK, the question is whether this phosphorylation is direct and, if so, what sites are being phosphorylated. Recent analysis of DDK site specificity has shown that DDK is an acid-directed, or phosphate-directed, protein kinase. In human Mcm2, DDK phosphorylation sites have been mapped to Ser or Thr residues immediately followed by a negatively charged or phosphorylated amino acid /Cho et al. 2006). Two groups independently found sites in human $\mathrm{Mcm} 2$ that are phosphorylated more efficiently by DDK after the adjacent C-terminal residue was first phosphorylated by CDK (Cho et al. 2006; Montagnoli et al. 2006). These sites both have the sequence TSSPGR, where the first (i.e., more $\mathrm{N}$-terminal) serine is a DDK site, and the second serine is a CDK site. Strikingly, an almost identical sequence, TSSPFR, occurs in Mer2, where the second (i.e., more C-terminal) serine is S30, the known site of phosphorylation by CDK-S. Therefore, phosphorylation of S30 by CDK-S could promote phosphorylation of S29 by DDK. The preceding residue, T28, is also phosphorylatable. If DDK is truly a phosphatedirected kinase, then phosphorylation of S29 could lead to phosphorylation of T28, thus creating a highly acidic patch of three phosphorylated residues in a row.

If S29 is phosphorylated by DDK, then the Mer2-S29Amyc5 protein should exhibit a change in protein mobility similar to that seen in $c d c 7$-as diploids in the presence of PP1. To test this possibility diploids containing MER2-myc5, mer2-S30A-myc5, mer2-S29A-myc5, and mer2-S29A S30A-myc5 were incubated in Spo medium for $4 \mathrm{~h}$ and the proteins immunoprecipitated from soluble extracts using $\alpha$-myc antibodies. Western blot analysis indicates that Mer2 phosphorylation is decreased in the mer2-S29A mutant (Fig. 1C). The fact that Mer2-S29A-myc5 and Mer2-S29A S30A-myc5 protein mobilities are similar suggests that the bulk of the Mer2 mobility shift is due to DDK phosphorylation. Furthermore, the loss of this shift after inactivation of DDK-as suggests that S29 is a target for DDK phosphorylation in vivo.

\section{Meiotic CDK-S kinase activity is independent of DDK}

While our model proposes that CDK-S phosphorylation at S30 facilitates DDK phosphorylation of S29, an alternative possibility would be if DDK phosphorylation activates CDK-S in meiosis. This idea was tested by transferring $c d c 7$-as diploids to Spo medium in the presence or absence of PP1 and precipitating CDK-S complexes at different times using Clb5-Gst (Fig. 2A). CDK-S activity was then monitored using histone $\mathrm{H} 1$ as the substrate. An increase in CDK-S kinase activity was observed as cells proceeded through meiosis, consistent with the literature (Stuart and Wittenberg 1998). This increase was independent of DDK activity, indicating that meiosis is similar to vegetative cells, where CDK-S activity does not require DDK (Fig. 2A; Nougarede et al. 2000). 


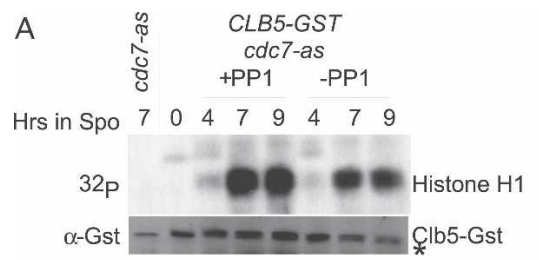

B

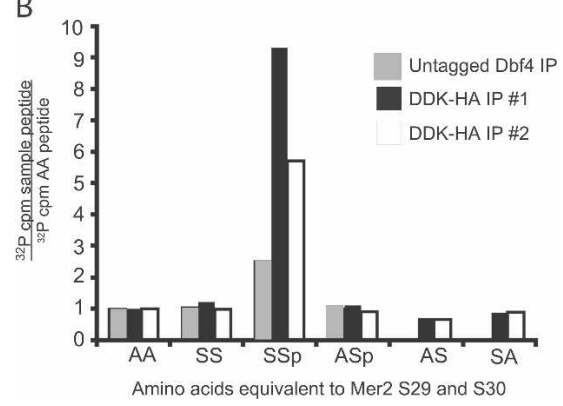

Figure 2. DDK and CDK-S in vitro kinase assays. (A) CDK-S kinase activity during meiosis in the presence or absence of active DDK. cdc7-as CLB5-GST (NH760) and cdc7-as (NH452F) diploids were sporulated at $30^{\circ} \mathrm{C}$ in the presence or absence of $15 \mu \mathrm{M}$ PP1. CDK-S activity was monitored using histone $\mathrm{H} 1$ as the substrate. The blot was probed with $\alpha$-Gst antibodies to detect Clb5-Gst. The asterisk marks a cross-reacting band that runs immediately below Clb5-Gst. (B) DDK activity: Soluble extracts from 334/pGO174 (7HA-DBF4) and 334 were used to immunoprecipitate Cdc7/7HA-Dbf4 complexes with $\alpha$-HA antibodies. Kinase assays were performed with these extracts using various biotinylated peptides containing the indicated amino acids corresponding to S29 and S30 of Mer2. Each reaction was normalized to the counts obtained for the reaction using DDK-HA complexes and the AA peptide. Two independent DDK-HA immunoprecipitates were assayed.

\section{Phosphorylation of S29 in vitro is enhanced by $S 30$ phosphorylation}

The idea that phosphorylation of S30 promotes DDK phosphorylation of S29 was directly tested by immunoprecipitating Cdc7/7HA-Dbf4 (DDK-HA) from vegetative yeast cells with $\alpha$-HA antibodies for use in in vitro protein kinase reactions with various peptides. As a negative control, a strain containing an untagged version of Dbf4 was included. Biotinylated peptides were used as substrates. Peptides had the structure $\mathrm{N}_{\text {term }}$-biotinGALAX $\mathbf{X}_{\mathbf{2 9}} \mathbf{X}_{\mathbf{3 0}}$ PFRAAG-C $\mathrm{C}_{\text {term }}$, where $\mathrm{X}_{29}$ and $\mathrm{X}_{30}$ represent positions 29 and 30 in Mer2, respectively. The bold sequence indicates the Mer2 CDK-S/DDK site. T28 was changed to alanine so that any phosphorylation that could potentially occur was limited to S29 or S30. The wild-type sequence has $\mathrm{SS}$ in the $\mathrm{X}_{29} \mathrm{X}_{30}$ sites. The negative control peptide has AA at these positions. ASp and SSp peptides contain phospho-serine in the $\mathrm{X}_{30}$ position. After incubation with the immunoprecipitated kinase and radioactively labeled ATP, the biotinylated peptides were captured onto streptavidin membranes, washed, and counted. Each kinase reaction was then normalized to the number of counts observed with the AA peptide incubated with an immunoprecipitate from the DDK-
HA strain. In two independent DDK-HA immunoprecipites, a five- to ninefold increase in radioactivity was observed for the SSp peptide over the AA control (Fig. 2B). This increase is dependent on both S29 and phosphoS30 (Fig. 2B). These results provide biochemical support for the idea that yeast DDK, like human DDK, has a preference for phosphorylating amino acids immediately upstream of a phosphorylated residue.

\section{S29 and T28 are important for Mer2 function}

Mutants were initially made in a tagged version of MER2, MER2-myc5, which has almost but not quite wild-type levels of MER2 function (Materials and Methods; Henderson et al. 2006). For simplicity, mer2 mutants are described by the amino acids present in the mutant protein in the order 28-29-30; e.g., wild-type MER2 is TSS. Substitution of S29 with alanine (mer2TAS-myc5) produced $\sim 1 \%$ viable spores, equivalent to mer2s and mer2-TSA-myc (mutant residues in bold) (Fig. 3A), showing that S30 alone, the known target of CDK-S phosphorylation, is not sufficient. A critical role for Mer2 S29 in meiosis has also been demonstrated by Sasanuma et al. (2008). mer2-ASS-myc5 also exhibits reduced spore viability, although the phenotype is not as severe as either TSA or TAS. In this case, changing T28 to aspartic acid (DSS) restores spore viability to wild-type levels (Fig. 3A). In combination with the biochemical experiments, these results are consistent with the idea that CDK-S phosphorylates S30, and that this primes the phosphorylation of S29 by DDK. In some cases, this may further prime the phosphorylation of T28 by DDK, creating an acidic patch three residues long.

Substitution of S30 with aspartic acid (TSD) (mimicking phosphorylation) gave spore viability of $\sim 11 \%$, indicating that the negative charge conferred by aspartic acid can partially compensate for the lack of S30 phosphorylation (Fig. 3A). Additional MER2 function can be restored to mer2-TSD-myc5 by introducing additional aspartic acid residues at S29 and/or T28. For example, DSD produced $58 \%$ viable spores, a significantly higher number than TSD (Fig. 3A). This improved spore viability requires S29, presumably due to its phosphorylation, as DAD produced only $5.8 \%$ viable spores. Having S29 flanked by negative charges may compensate for the absence of a phosphate at S30 in promoting DDK phosphorylation at this site. Substituting aspartic acid at all three positions resulted in $71.5 \%$ viable spores (Fig. 3A). Viability is improved to wild-type levels if the DDD mutations are homozygous in an untagged allele of MER2 (Fig. 3A, right). The high spore viability of mer2-DDD suggests that CDK-S and DDK phosphorylation of Mer2 can be bypassed under otherwise wild-type conditions without drastically affecting meiotic recombination.

Meiotic DSB formation requires a negative charge at S29 and S30

Meiotic time-course analysis of DSBs at the YCR048W hot spot shows that DSB formation is abolished by mer2- 
Wan et al.

Figure 3. Phenotypic analysis of mutants in the TSS site of Mer2. (A) Spore viability: mer2s diploids (NH782) containing two copies of plasmids carrying either MER2myc5 and derivatives or MER2 and mer2$D D D$ were sporulated and a minimum of 26 asci were dissected. (B) Time-course analysis of mer2-S29A-myc5: MER2-myc5 (NH782::pKH35) and mer2-S2A-myc5 (NH782::pKH35-S29A) diploids were sporulated at $30^{\circ} \mathrm{C}$ and DSBs were monitored at the YCR048w hot spot. (C) DSBs in mer2 sae2s mutants: A mer2s sae2s diploid (NH837) containing two copies of the indicated mer2-myc5 alleles was sporulated for 8 $\mathrm{h}$ at $30^{\circ} \mathrm{C}$. DSBs were monitored at the YCR048W hot spot. (D) Quantitation of DSBs in C. $(E)$ Time-course analysis of mer2$D D D$ : NH782 containing two copies of either MER2 or mer2-DDD were sporulated at $30^{\circ} \mathrm{C}$ and DSBs were monitored at the YCR048w hot spot. (F) Quantitation of DSBs in E. $(G)$ Meiotic progression in the time course shown in $E$.
A

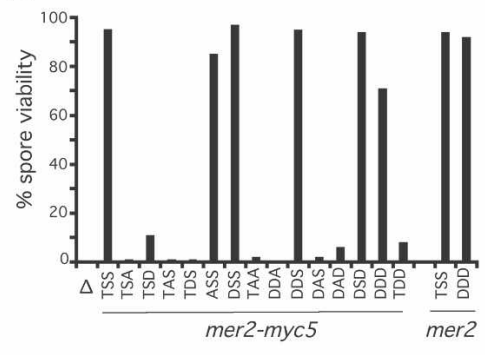

C mer2-myc5 sae2 $\triangle$

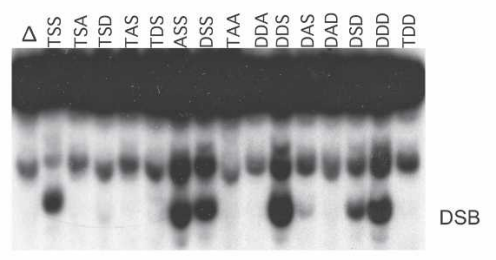

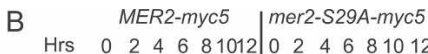

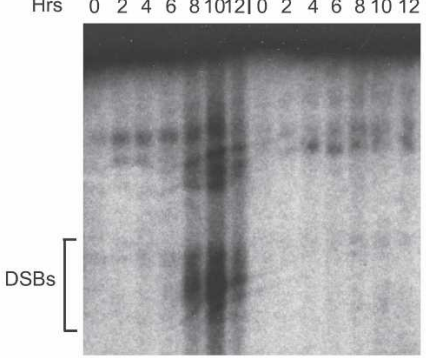

D

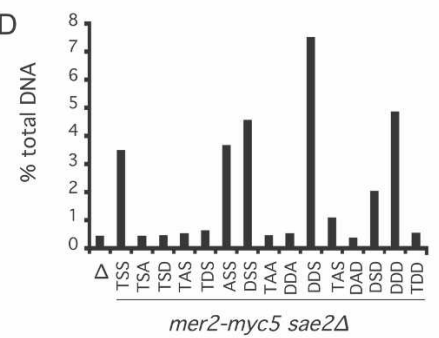

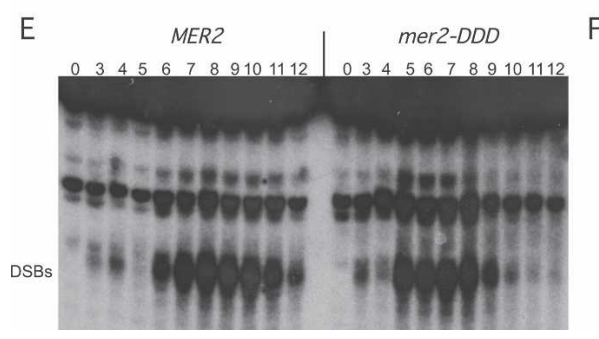

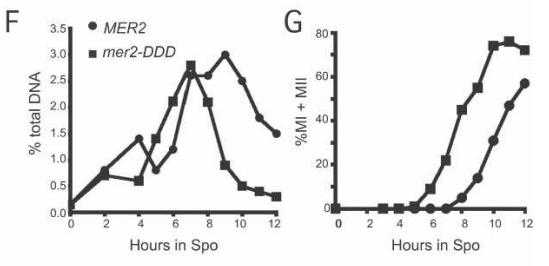

TAS-myc5 (Fig. 3B). To increase the chances of detecting a low level of meiotic DSBs, various mer2-myc5 mutants were integrated in two copies into an sae $2 \Delta / \operatorname{com} 1$ diploid, which fails to resect DSBs, thereby allowing them to accumulate (McKee and Kleckner 1997; Prinz et al. 1997). Like mer2-TSA-myc5, mer2-TAS-myc5 sae2d exhibited no DSBs, confirming that 229 is just as critical as S30 for the initiation of meiotic recombination in yeast (Fig. 3C,D). The ability of a mer2 allele to generate viable spores correlates very well with its ability to make DSBs. mer2-ASS, DSS, DDS, DSD, and DDD all exhibited at least $80 \%$ viable spores when present in two copies and produced DSBs at or above wild-type levels (Fig. 3A,C,D).

DSBs in a diploid carrying two copies of mer2-DDD were also examined in an otherwise wild-type background by time-course analysis. In all experiments, DSBs in the mer2-DDD diploid occurred at similar levels as wild-type (Fig. 3E,F). Some variability in the kinetics of DSB formation and meiotic progression were observed between experiments (Fig. 3G; data not shown).

A negative patch at the TSS site of Mer2 does not bypass the requirement for DDK or CDK-S for DSB formation

To test whether the negative charges conferred by aspartic acids at S30, S29, and T28 bypass the requirement for
DDK phosphorylation, mer2-DDD-myc5 and mer2$D D D$ were introduced in two copies into a cdc7-as diploid. Although both MER2-myc5 and MER2 produced wild-type levels of viable spores in combination with $c d c 7-a s$, a synergistic decrease in spore viability was observed between mer2-DDD-myc5 and cdc7-as. cdc7-as and mer2-DDD-myc5 alone produced $>90 \%$ and $71 \%$ viable spores, respectively, while diploids containing both mutations exhibited $<2 \%$ spore viability (Figs. 3A, 4A). Two copies of untagged mer2-DDD improved spore viability to $\sim 40 \%$, but this value is still significantly lower than the $>90 \%$ observed for the mer2-DDD CDC7 diploid (Figs. 3A, 4A). Overexpressing mer2-DDD increased spore viability in the cdc7-as background, suggesting that Mer2-DDD activity is limiting under these conditions (Fig. 4A). Therefore, cdc7-as exhibits a synthetic interaction with mer2-DDD with regard to spore viability.

To determine whether mer2- $D D D$-mediated DSBs can occur independently of DDK, mer2-DDD was overexpressed in a $c d c 7-a s$ sae2 $\Delta$ diploid. After $8 \mathrm{~h}$ in Spo medium, DSBs at the YCR048w hot spot were easily detected in the MER2 and mer2-DDD diploids without inhibitor (Fig. 4B,C). Addition of PP1 at $0 \mathrm{~h}$ eliminated DSBs in both diploids, indicating that DSB formation in the mer2-DDD strain still requires DDK activity (Fig. $4 \mathrm{~B}, \mathrm{C})$.

A similar experiment was performed using mer2- $D D D$ in a $c d c 28$-as sae2s background to test whether Mer2 is 
A

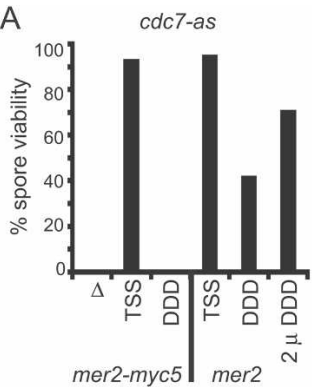

B $\quad$ dc 7 -as sae $2 \Delta$

$\triangle M E R 2 D D D$

PP1

$-\mid+++$
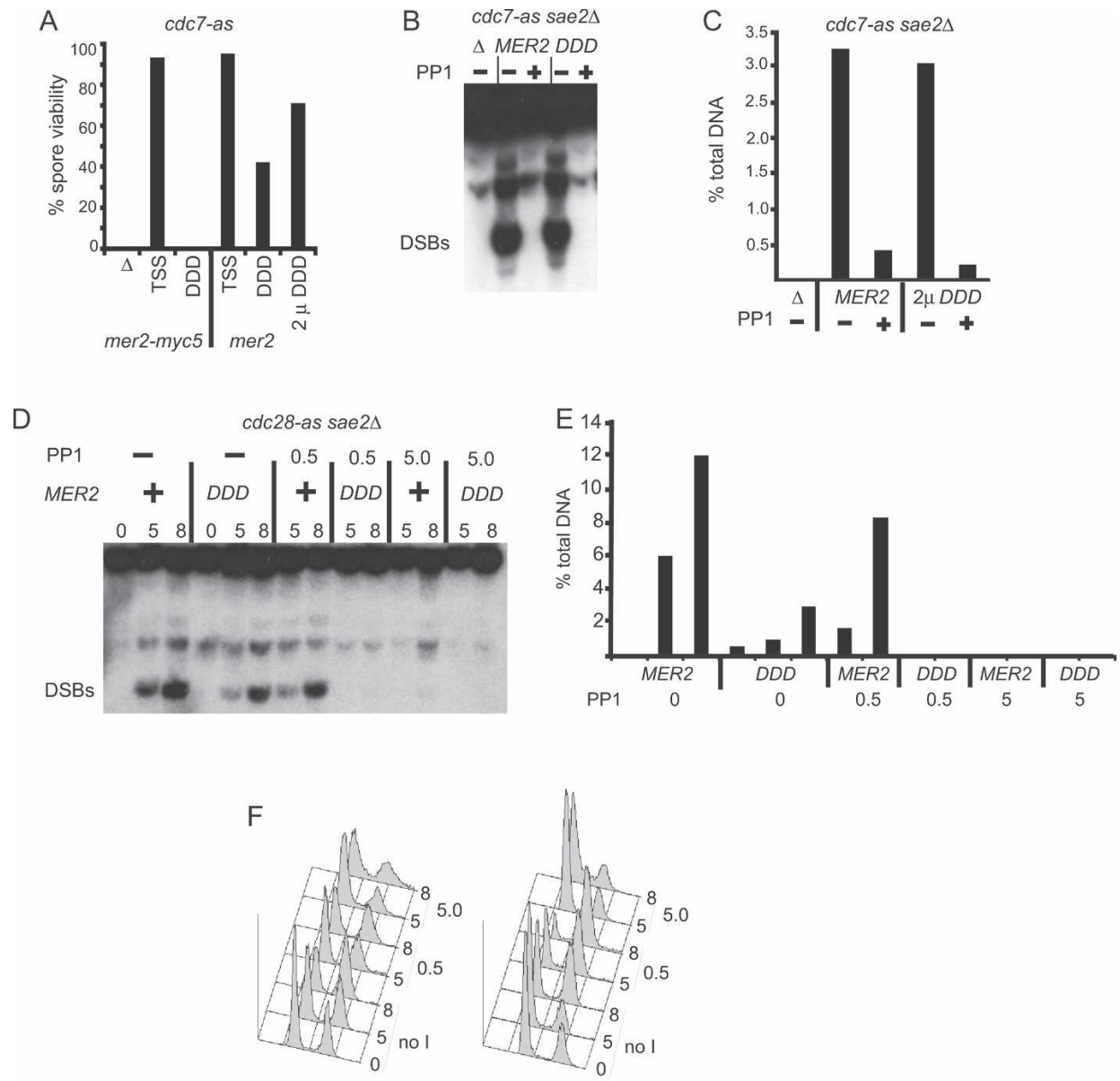

MER2 cdc28-as

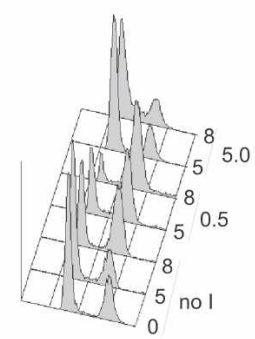

mer2-DDD cdc28-as

Figure 4. mer2-DDD phenotypes in the presence or absence of DDK or CDK activity. (A) Spore viability of diploids (NH780) containing either $c d c 7$-as mer2-DDD-myc5 or $c d c 7$-as mer2-DDD. A minimum of 26 asci were dissected. (B) DSBs in mer2-DDD cdc7-as sae2s diploids with and without PP1. NH828 carrying $2 \mu$ MER2 or mer2-DDD was sporulated for $8 \mathrm{~h}$ in the presence $(+)$ or absence $(-)$ of $15 \mu \mathrm{M}$ PP1 as indicated and monitored for DSBs at the YCR048w hot spot. (C) Quantitation of DSB gel shown in B. (D) DSBs in mer2-DDD cdc28-as sae2s diploids containing different amounts of 1-NM-PP1 inhibitor. NH888 carrying two integrated copies of MER2 or mer2-DDD was sporulated in the presence of the indicated amount (in micromolar) of 1-NM-PP1. DSBs were monitored at 0,5 , and $8 \mathrm{~h}$ after transfer to Spo medium. $(E)$ Quantitation of DSB gel shown in $D$. $(F)$ Flow cytometry analysis of cells from time course shown in $D$.

the sole target of CDK-S for generating DSBs. Spore viability with two copies of integrated mer2-DDD in the cdc28-as diploid was $>90 \%$, indicating perhaps that the cdc28-as allele is more functional than cdc7-as. Inhibition of Cdc28-as results in two arrest points during meiosis, depending on the concentration of inhibitor. Low levels of 1-NM-PP1 $(0.5 \mu \mathrm{M})$ result in a pachytene arrest after DSB formation, while $5.0 \mu \mathrm{M}$ blocks prior to premeiotic S (Benjamin et al. 2003). These results were reproduced in our MER2 cdc28-as sae2s strain as both DNA replication and DSB formation were observed with 0 and $0.5 \mu \mathrm{M}$ inhibitor but not with $5 \mu \mathrm{M}$ inhibitor (Fig. $4 \mathrm{D}, \mathrm{E}, \mathrm{F})$. The frequency of DSBs was greatly reduced when mer2-DDD was combined with $0.5 \mu \mathrm{M}$ inhibitor (although premeiotic $S$ was unaffected), indicating that mer2-DDD sensitizes the cells to decreased levels of CDK activity. This result, combined with an absence of breaks in mer2-DDD diploid with $5.0 \mu \mathrm{M}$ 1-NM-PP1 shows that negative charges at the TSS site of Mer2 do not bypass the requirement for CDK phosphorylation of other targets.

The DDK-CDK combination site is conserved in Mer2 in other yeasts

If both DDK and CDK phosphorylation of Mer2 are important, then the combination site should be conserved in other yeasts. We examined Mer2 in relatively close (sensu stricto) and relatively distant relatives of Saccharomyces cerevisiae (Fig. 5; Wolfe 2006). All close relatives preserved the entire combination site; i.e., TSSPxR. More distant relatives lacked the " $\mathrm{T}$ " residue, but nevertheless still preserved a DDK-CDK combination site, $\operatorname{SSPx}(\mathrm{K} / \mathrm{R})$, or SSPxxK. The exception is Candida glabrata. This yeast has a good Mer2 ortholog (e- 
Wan et al.

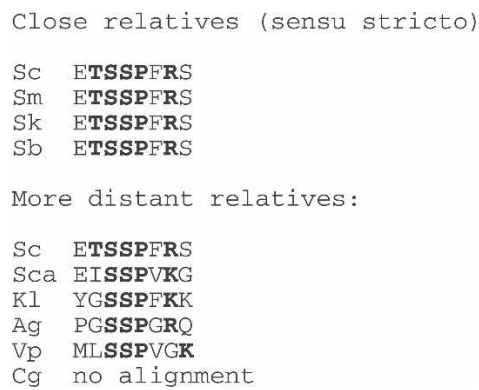

Figure 5. Conservation of the DDK-CDK combination site in Mer2 orthologs from other fungi. Mer2 orthologs were identified by three iterations of Psi-Blast (NCBI) using residues 24-150 of Mer2 and the "TSSPFR" region was aligned by eye. In Vanderwaltozyma polyspora, the basic residue in the CDK site is at +4 instead of +3 , but this is still an excellent CDK site. (Sc) S. cerevisiae; (Sm) Saccharomyces mikatae; (Sk) Saccharomyces kudriavzevii; (Sb) Saccharomyces bayanus; (Sca) Saccharomyces castellii; (Kl) Kluyveromyces lactis; (Ag) Ashbya gossypii; (Vp) V. polyspora; (Cg) C. glabrata.

value $\left.=10^{-22}\right)$, but it lacks any semblance of an $\operatorname{SSPx}(\mathrm{K} /$ R) motif (Fig. 5). However, this yeast has not been observed to undergo meiosis, and therefore may not require meiotic regulation of Mer2.

A $D D K-C D K$ combination site is a powerful predictor of involvement in the cell cycle

A DDK-CDK site might be a general motif for dual regulation of protein function by a combination of DDK and CDK kinases. A search of the yeast proteome for the DDK/CDK combination site S-(S/T)-P-X-(K/R) yielded 246 proteins. Of these, seven had three sites, 24 had two sites, and 215 had one site. These proteins represent a subset of proteins with CDK sites.

The question is whether the presence of a combination $\mathrm{DDK} / \mathrm{CDK}$ site in a protein is a better predictor of involvement in the cell cycle than the presence of a CDK site alone. A DDK/CDK combination site has slightly more sequence information than a single CDK site, but less information than two CDK sites. Therefore, to do a conservative comparison, 215 proteins with a single DDK/CDK combination site were compared with 215 randomly selected proteins containing two CDK sites. The "GO terms" used in the annotation of the Saccharomyces Genome Database (SGD) were used to assign functions to each protein. GO term enrichment showed unexpectedly that two CDK sites were not enough to enrich for cell cycle proteins (although three or more CDK sites were sufficient) (Table 1; data not shown). However, even a single DDK/CDK site strongly enriched for cell cycle proteins (Table 1). Thus, a single DDK/ CDK combination site is a better predictor of cell cycle involvement than one or even two CDK sites.

Inspection of the proteins with one or more DDK/ CDK combination sites (Supplemental Table S2) shows many proteins involved in replication, recombination, and repair, as expected from the known roles of DDK. In addition, the proteins were highly enriched for proteins involved in chromosome segregation (e.g., Cdc15, Lte1, Acc1, Kic1, Ase1, Ask1, Sfi1, Stu2, Nbp1, Spc29, Spc98, Kar1, Kip2, Mps2, Mps3, Swe1, Bir1, Kcc4, Sli15, Cnn1, Cdh1, and others). DDK does not have a known role in mitotic chromosome segregation, but such a role might be difficult to discern, since $c d c 7^{t s}$ mutants arrest before DNA replication and therefore never reach mitosis. Furthermore, at least two previous studies have linked Cdc7 or its activator Dbf4 to the mitotic polo-like kinase Cdc5 (Kitada et al. 1993; Hardy and Pautz 1996), while more recent work has indicated a role for DDK in Meiosis I chromosome segregation (Valentin et al. 2005; our unpublished results). If DDK does have a role in mitotic chromosome segregation, it is likely a nonessential role, since a $c d c 7$ deletion can be suppressed by a point mutation in the replication protein Mcm5 (Hardy et al. 1997).

\section{Discussion}

$C D K-S$ regulates DSB formation by priming Mer2 for phosphorylation by DDK: implications for regulation of meiosis

There are many protein kinases that have an acidic or phosphorylated residue in their consensus phosphorylation site, and some of these are "primed" by other protein kinases. That is, the first kinase provides a negative charge allowing phosphorylation by the second kinase. One example of a primed protein kinase is Gsk3 (Mds1 in yeast), which, by responding to and integrating signals from other protein kinases, participates in many signaling pathways (Doble and Woodgett 2003; Kockeritz et al. 2006; Forde and Dale 2007). Another example is casein kinase (Cka1 and Cka2 in yeast) (Bustos et al. 2005). In general, the priming of one protein kinase by another has at least two effects: First, it places a process under the control of two kinases; i.e., the process does not happen unless both kinases are active. Second, priming increases substrate specificity, since the substrate must have a site for both kinases.

Here, the sequential CDK/DDK phosphorylation of Mer2 on Ser30 and then Ser29 places Mer2 and meiotic recombination under the control of both CDK and DDK protein kinases. These two kinases act not only in meiosis, but also in mitotically dividing cells, where, for instance, they are both required to initiate DNA replication (Bell and Dutta 2002). Experiments in mitotically dividing budding yeast cells indicate that CDK-S acts prior to DDK (Nougarede et al. 2000). One explanation for this functional order is that CDK-S phosphorylation primes proteins for subsequent DDK phosphorylation. Support for this idea comes from biochemical studies that have shown that prior phosphorylation by $\mathrm{CDK}$ stimulates phosphorylation of an immediately adjacent upstream serine by DDK (Masai et al. 2000, 2006; Cho et al. 2006; Montagnoli et al. 2006). However, the functional relevance of the coordinated phosphorylation of a replication protein by CDK-S and DDK has not yet been 
Table 1. Proteins with a single DDK-CDK combination site have cell cycle functions

\begin{tabular}{|c|c|c|c|}
\hline Site requirement & Number of proteins ${ }^{\mathrm{a}}$ & GO terms enriched & $P$-value ${ }^{\mathrm{b}}$ \\
\hline \multirow[t]{3}{*}{$\mathrm{CDK}$ sites $\geq 2$} & \multirow[t]{3}{*}{403} & Cell cycle process & $10^{-21}$ \\
\hline & & Cell cycle & $10^{-20}$ \\
\hline & & Mitotic cell cycle & $10^{-16}$ \\
\hline \multirow[t]{3}{*}{$\mathrm{DDK} / \mathrm{CDK}$ sites $\geq 1$} & \multirow[t]{3}{*}{246} & Cell cycle process & $10^{-14}$ \\
\hline & & Cell cycle & $10^{-14}$ \\
\hline & & Mitotic cell cycle & $10^{-9}$ \\
\hline \multirow[t]{2}{*}{$\mathrm{CDK}$ sites $=2$} & \multirow[t]{2}{*}{215} & Cell. Component organization, biogenesis & $10^{-8}$ \\
\hline & & Cell morphogenesis & $10^{-4}$ \\
\hline \multirow[t]{3}{*}{$\mathrm{DDK} / \mathrm{CDK}$ sites $=1$} & \multirow[t]{3}{*}{215} & Cell cycle process & $10^{-10}$ \\
\hline & & Cell cycle & $10^{-10}$ \\
\hline & & Mitotic cell cycle & $10^{-5}$ \\
\hline
\end{tabular}

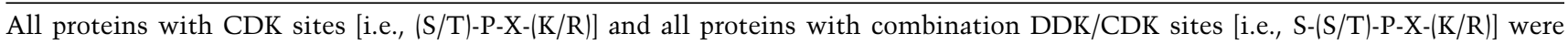
found using Pat Match (SGD). Note that neither "cell cycle process" nor "mototic cell cycle" was a significantly enriched GO term for the 215 two-site CDK proteins, but strong enrichment was observed for the 215 one-site DDK/CDK proteins.

${ }^{a}$ The number of proteins used for the GO term search.

${ }^{\mathrm{b}} P$-value is the order of magnitude of the $P$-value.

established. Recently, it was shown that Sld2 and Sld3 are the only essential targets of CDK-S in budding yeast for replication initiation (Tanaka et al. 2007; Zegerman and Diffley 2007). These authors found that conditions that bypass CDK-S phosphorylation still require DDK activity for replication, suggesting that DDK has functions that are independent of CDK-S. To our knowledge, the ordered phosphorylation of Mer2 by CDK-S and DDK to initiate meiotic DSB formation represents the first example of a process regulated by the sequential action of these two kinases on a single protein.

The fact that proteins containing a DDK/CDK combination site are highly enriched for cell cycle functions is consistent with the idea that CDK/DDK priming events may involve many other proteins in addition to Mer2. These would likely include DNA replication proteins, and also proteins involved in recombination, repair, and perhaps chromosome segregation in both mitosis and meiosis.

Control by the same pair of protein kinases might allow some of these events to be properly coordinated with each other. In wild-type cells, DSBs are formed only after sequences have been replicated. This result was demonstrated by elegant experiments in which DNA replication along one chromosome arm was delayed by deleting the origins along that arm and showing that DSBs along the arm were coordinately delayed (Borde et al. 2000). However, DSBs have been observed under conditions where premeiotic $S$ is blocked, indicating that the DSB requirement for replication is not absolute (Murakami and Nurse 2001; Hochwagen et al. 2005). Possibly the concerted action of CDK-S and DDK in both premeiotic $\mathrm{S}$ and DSB formation is somehow responsible for ensuring that DSBs occur only in replicated sequences. For example, passage of the replication fork could result in CDK-S phosphorylation of Mer2, thereby marking the Mer2 on replicated DNA for DDK phosphorylation.

Finally, DDK phosphorylation may be primed during meiosis by other kinases in addition to CDK. For example, one possible candidate is the serine/threonine ki- nase Ime2, which is needed for meiosis and seems to control some of the same events as DDK (Sopko et al. 2002; Benjamin et al. 2003; Clifford et al. 2005). Thus, in meiosis, DDK might integrate signals from several protein kinases. Other more complex regulatory relationships are also possible. For example, we note that the site for DDK phosphorylation, Ser-pSer-Pro, matches the docking site for polo kinase (Cdc5 in yeast) (Kitada et al. 1993; Hardy and Pautz 1996; Elia et al. 2003; Valentin et al. 2005). Thus, phosphorylation of a protein by DDK could inhibit Cdc5 binding. Relationships between Cdc7 and Cdc5 have been noted previously (Kitada et al. 1993; Hardy and Pautz 1996; Valentin et al. 2005).

\section{A negatively charged 'patch' at the TSS site on Mer2 is essential for function:Is T28 phosphorylated?}

We find that CDK phosphorylation of S30 (Henderson et al. 2006) primes DDK phosphorylation at S29, which may prime phosphorylation of T28 (Fig. 6). Thus, a negatively charged "patch" of two or three adjacent phosphoamino acids is created, allowing formation of a complex between Mer2, Mei4, and Rec114.

The TDD mutant does not function efficiently for DSB formation or spore viability, but this defect can be largely suppressed by a further mutation to DDD or by allowing phosphorylation of S29 and S30 (ASS). These results can be interpreted in at least two ways. First, it may be that a patch of three phosphorylated amino acids is required for full function. Alternatively, it may be that a total of three or four negative charges are required, but not necessarily spread over three amino acids. Since a phosphate provides two negative charges, and aspartate only one, the DDD mutant may approximate the charge that would occur if both S29 and S30 were phosphorylated. A similar effect has been seen with Ste5 (Strickfaden et al. 2007). The best evidence for the functional importance of phosphorylation of T28 is that the ASS mutant has a small defect in spore viability that can be suppressed by DSS (Fig. 3A). However, the effect is small, 
Wan et al.

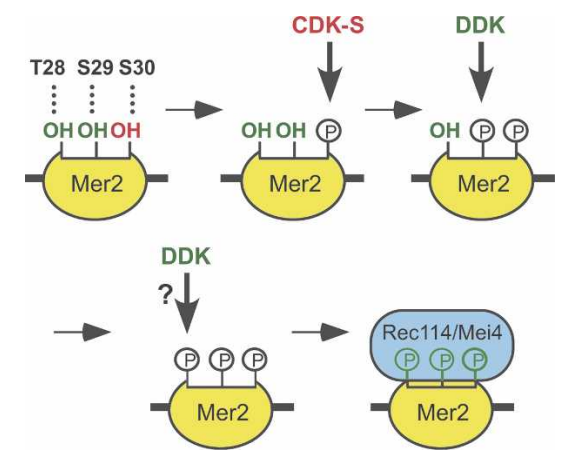

Figure 6. Model for sequential phosphorylation of Mer2 by CDK-S and DDK. Phosphorylation of Mer2 at S30 results in a negative charge that enhances DDK phosphorylation at S29. The charge at S29 may then promote phosphorylation of T28 by $\mathrm{DDK}$, creating a negatively charged patch that is necessary for interaction of Mer2 with Mei4 and Rec114. (Red OH group) CDK-S target S30; (green OH groups) DDK targets T28 and S29.

and the evidence for phosphorylation of T28 remains suggestive.

\section{$D D K$ and $C D K$-S have additional targets for meiotic} DSB formation besides the TSS sequence on Mer2

Although mer2-DDD complements the spore viability defect of mer2s, it does not bypass either DDK or CDK activity for making DSBs. Thus, these two kinases presumably have substrates other than Mer2-S29 or S30 that are important for recombination. Additional phosphorylation sites could be present in other proteins, or they could be present elsewhere in Mer2. There are several potential DDK phosphorylation sites in the Mer2 N terminus ( $\mathrm{T}$ or $\mathrm{S}$ followed by a negative charge) and mutation of all of these sites creates a nonfunctional mer2 mutant (Sasanuma et al. 2008). In addition, there is a second potential DDK/CDK-S combination site near the $\mathrm{C}$ terminus of Mer2. However, the functional importance of this site is unclear. In contrast to S29 and S30, where single amino acid substitutions to alanine create null mer2 alleles, mutation of the equivalent serines in the downstream position (S270 and S271) has no effect (Henderson et al. 2006; L. Wan and N.M. Hollingsworth, unpubl.). Possibly the N-terminal site (S29 S30) is sufficient, but when this $\mathrm{N}$-terminal site is compromised, the C-terminal site (S270 S271) becomes important.

\section{Phosphorylation regulates temporally and mechanistically distinct steps in meiotic recombination}

Meiotic recombination requires DSB formation, resection, and strand invasion of homologs, followed by repair synthesis and double Holliday junction resolution. This work shows that phosphorylation of proteins involved in mechanistically different steps of recombination occurs at different times and most likely by different kinases. Phosphorylation of Mer2 by CDK-S and DDK is required for making protein complexes with Rec114 and/or Mei4 that in turn are needed to recruit Rec114 and Mei4 to DSB sites as a prerequisite for Spol1 binding (Henderson et al. 2006; Sasanuma et al. 2008). Phosphorylation of Mer2 should therefore precede DSB formation, a prediction we confirmed using the $c d c 7$-as washout system. In contrast, phosphorylation of Hop1 occurs after DSBs have been made, consistent with its role in the activation of Mek1 as part of a mechanism that suppresses strand invasion of sister chromatids, thereby promoting recombination between homologs (Niu et al. 2005). Although inactivation of DDK prevents Hopl phosphorylation, this is likely to be an indirect effect resulting from the absence of DSBs (Wan et al. 2006). Phosphorylation clearly plays a critical role in the mechanisms underlying various meiotic processes such as recombination and segregation, as well as in coordinating these processes to occur in a precise order. Defining the kinases, substrates, and phosphorylation sites involved in these processes is therefore an important goal for understanding meiosis.

\section{Materials and methods}

\section{Plasmids}

MER2 (pKH20), MER2-MYC5 (pKH35), and mer2-myc5-S30A (pKH36) were provided by Scott Keeney (Sloan Kettering Cancer Center) (Henderson et al. 2006). mer2-myc5 mutants were created by site-directed mutagenesis using pKH35 as a template (QuikChange kit, Stratagene). Plasmid pGO174 (7HA-DBF4 CEN ARS URA3) was provided by Bob Sclafani (University of Colorado Health Sciences Center) (Dohrmann et al. 1999). pNH256 is a URA3-integrating plasmid containing cdc7-as. pEJ7 carries mer2-DDD in a URA3-integrating plasmid. pLW67 and pLW68 are $2 \mu U R A 3$ plasmids containing MER2 and mer2$D D D$, respectively. Details of plasmid constructions are available upon request.

\section{Strains}

334 is derived from the A364a strain background (Hovland et al. 1989). All other strains were derived from the SK1 background. Complete genotypes for each strain can be found in Supplemental Table 1. Details of strain constructions are available upon request.

\section{Immunoprecipitations and Western blots}

Mer2-myc8 was immunoprecipitated with an equal volume of 9E10 culture supernatant, and was detected with a 1:10 dilution of 9E10. Mer2-myc5 was immunoprecipitated with an equal volume of 9E10 culture supernatant and detected with polyclonal $\alpha$-rabbit myc antibodies at a 1:5000 dlution (Abcam). Hop1 was immunoprecipitated and detected as described in Niu et al. (2005).

\section{Peptides}

Peptides were synthesized by the Peptide Synthesis Laboratory, Cancer Research UK. The peptides were dissolved in water at a concentration of $5 \mathrm{mg} / \mathrm{mL}$. 


\section{Inhibitor}

Stocks of $10 \mathrm{mM}$ PP1 were synthesized at the University of California at San Francisco as described in Bishop et al. (1999).

\section{In vitro kinase assays}

For the peptide labeling experiment, $700 \mathrm{~mL}$ of log-phase cultures were grown in SD-ura $\left(2 \times 10^{9}\right.$ cells $)$, washed with $10 \mathrm{~mL}$ of cold lysis buffer (50 mM HEPES at $\mathrm{pH} 7.5,100 \mathrm{mM} \mathrm{Na}$ acetate, $10 \%$ glycerol, $5 \mathrm{mM}$ EDTA, $2 \mathrm{mM}$ benzamide, $10 \mathrm{mM}$ $\mathrm{NaF}, 1 \mathrm{mM}$ PMSF, l, and resuspended in $0.3 \mathrm{~mL}$ of lysis buffer in $2 \mathrm{~mL}$ screw-cap microfuge tubes (Sarstedt). Zirconia-silica beads (0.5 mm; Biospec) were added to a volume of $1.2 \mathrm{~mL}$ and the cells were lysed using a FastPrep instrument (Qbio-gene) with four 20-sec pulses at speed 4 . After bead beating, 10\% NP-40 was added to a final concentration of $0.5 \%(25 \mu \mathrm{L})$. The tube was punctured on the bottom with a 30.5-gauge needle and placed into a $15-\mathrm{mL}$ conical tube, and the lysate was collected by centrifugation for $30 \mathrm{sec}$ with a tabletop centrifuge. One-hundred microliters of lysis buffer were added to the beads and the tube was centrifuged again to collect the wash, which was pooled with the initial lysate. The extract was cleared by spinning at $16,000 \mathrm{rpm}$ in an Eppendorf microfuge for $10 \mathrm{~min}$. To try to remove biotin from the extract, $200 \mu \mathrm{L}$ of a 1:1 slurry of streptavidin beads (Active Motif) were first washed four times with $1 \mathrm{~mL}$ of lysis buffer and then added to the soluble extract, which was incubated for $15 \mathrm{~min}$ on ice with vortexing every $2 \mathrm{~min}$. The beads were removed by two 4 -min spins at 16,000 rpm. HA antibody was prebound to beads by incubating $60 \mu \mathrm{L}$ of Protein G beads (GE Healthcare) pre-equilibrated in lysis buffer with 2.5 $\mu \mathrm{L}$ of $12 \mathrm{CA} 5$ antibodies (in ascites fluid) for $15 \mathrm{~min}$ on ice. The antibody-bead complexes were washed four times with $1 \mathrm{~mL}$ of lysis buffer, resuspended with $60 \mu \mathrm{L}$ of lysis buffer, and added to the soluble extract to immunoprecipitate 7HA-Dbf4. The samples were incubated for $1.5 \mathrm{~h}$ at $4^{\circ} \mathrm{C}$ on a rotating platform. The immunoprecipitates were washed four times with $1 \mathrm{~mL}$ of lysis buffer and once with $1 \mathrm{~mL}$ of kinase buffer $(25 \mathrm{mM}$ HEPES at $\mathrm{pH} 7.5,100 \mathrm{mM} \mathrm{Na}$ acetate, $10 \mathrm{mM} \mathrm{MgCl}_{2}, 10 \%$ glycerol, 0.1 mM DTT, $0.1 \mathrm{mM}$ PMSF, $5 \mu \mathrm{M}$ ATP) and resuspended in $60 \mu \mathrm{L}$ of kinase buffer. Kinase reactions contained $10-\mu \mathrm{L}$ beads from the immunoprecipitate, $1 \mu \mathrm{L}$ of peptide $(1 \mathrm{mg} / \mathrm{mL})$, and $1 \mu \mathrm{L}$ of ${ }^{32} \mathrm{P}-\boldsymbol{\gamma}$-ATP (5000 Ci//mmol), and were performed for $30 \mathrm{~min}$ at room temperature. The reactions were stopped by addition $6 \mu \mathrm{L}$ of $7.5 \mathrm{M}$ guanidine $\mathrm{HCl}$. Twelve microliters were spotted onto a $1-\mathrm{mm}^{2}$ piece of $\mathrm{SAM}^{2}$ Biotin Capture Membrane (Promega). After sitting at room temperature for $2 \mathrm{~min}$, the membrane squares were washed in bulk with $100 \mathrm{~mL}$ of $2 \mathrm{M} \mathrm{NaCl}(1 \times 30$ sec, followed by $3 \times 2 \mathrm{~min}), 100 \mathrm{~mL}$ of $2 \mathrm{M} \mathrm{NaCl}$ plus $1 \% \mathrm{H}_{3} \mathrm{PO}_{4}$ $(4 \times 2 \mathrm{~min})$, and $100 \mathrm{~mL}$ of water $(2 \times 30 \mathrm{sec})$, and air dried. The number of radioactive counts on each membrane was then assayed using a scintillation counter.

CDK-S activity was assayed by purifying Clb5-Gst from $c d c 7$ as sporulating cells incubated with and without $15 \mu \mathrm{M}$ PP1 as described in Wan et al. (2004). Kinase assays were performed using the precipitates as described in Neiman and Herskowitz (1994) with the addition to Histone $\mathrm{H} 1$ to a final concentration of $200 \mathrm{ng} / \mu \mathrm{L}$. The proteins were fractionated on a $15 \%$ SDS polyacrylamide gel, transferred to a nitrocellulose filter, and exposed to film. The blot was then probed with a 1:5000 dilution of $\alpha$-Gst antibodies.

Sporulation, time courses, and PP1 washout

Cells were sporulated at a density of $3 \times 10^{7}$ cells per milliliter at $30^{\circ} \mathrm{C}$. PP1 was washed out after $8 \mathrm{~h}$ in Spo medium as described in Wan et al. (2006).

\section{Acknowledgments}

We are grateful to Scott Keeney and Aaron Neiman for helpful discussions and comments on the manuscript. In addition, Scott Keeney provided plasmids and shared unpublished results. Thanks to Bob Sclafani and Neta Dean for plasmids and antibodies, respectively, and Adam Rosebrock for computer help. Emily Job provided excellent technical support. N.M.H. is supported by NIH grant GM50717, S.J.B. is supported by Cancer Research UK, K.M.S. is supported by AI44009, and B.F. is supported by NIH grant GM64813.

\section{References}

Arora, C., Kee, K., Maleki, S., and Keeney, S. 2004. Antiviral protein Ski8 is a direct partner of Spol1 in meiotic DNA break formation, independent of its cytoplasmic role in RNA metabolism. Mol. Cell 13: 549-559.

Bell, S.P. and Dutta, A. 2002. DNA replication in eukaryotic cells. Annu. Rev. Biochem. 71: 333-374.

Benjamin, K.R., Zhang, C., Shokat, K.M., and Herskowitz, I. 2003. Control of landmark events in meiosis by the CDK Cdc28 and the meiosis-specific kinase Ime2. Genes \& Dev. 17: 1524-1539.

Bishop, D.K., Park, D., Xu, L., and Kleckner, N. 1992. DMC1: A meiosis-specific yeast homolog of $E$. coli recA required for recombination, synaptonemal complex formation and cell cycle progression. Cell 69: 439-456.

Bishop, A.C., Kung, C.-Y., Shah, K., Witucki, L., Shokat, K.M., and Liu, Y. 1999. Generation of monospecific nanomolar tyrosine kinase inhibitors via a chemical genetic approach. $J$. Am. Chem. Soc. 121: 627-631.

Borde, V., Goldman, A.S., and Lichten, M. 2000. Direct coupling between meiotic DNA replication and recombination initiation. Science 290: 806-809.

Bustos, V.H., Marin, O., Meggio, F., Cesaro, L., Allende, C.C., Allende, J.E., and Pinna, L.A. 2005. Generation of protein $\mathrm{Ck} 1 \alpha$ mutants which discriminate between canonical and non-canonical substrates. Biochem. J. 391: 417-424.

Cho, W.H., Lee, Y.J., Kong, S.I., Hurwitz, J., and Lee, J.K. 2006. CDC7 kinase phosphorylates serine residues adjacent to acidic amino acids in the minichromosome maintenance 2 protein. Proc. Natl. Acad. Sci. 103: 11521-11526.

Clifford, D.M., Stark, K.E., Gardner, K.E., Hoffmann-Benning, S., and Brush, G.S. 2005. Mechanistic insight into the Cdc28related protein kinase Ime2 through analysis of replication protein A phosphorylation. Cell Cycle 4: 1826-1833.

Doble, B.W. and Woodgett, J.R. 2003. GSK-3: Tricks of the trade for a multi-tasking kinase. J. Cell Sci. 116: 1175-1186.

Dohrmann, P.R., Oshiro, G., Tecklenburg, M., and Sclafani, R.A. 1999. RAD53 regulates DBF4 independently of checkpoint function in Saccharomyces cerevisiae. Genetics 151: 965-977.

Elia, A.E.H., Rellos, P., Haire, L.F., Chao, J.W., Ivins, F.J., Hoepker, K., Mohammad, D., Cantely, L.C., Smerdon, S.J., and Yaffe, M.B. 2003. The molecular basis for phosphodependent substrate targeting and regulation of Plks by the Polo-Box domain. Cell 115: 83-95.

Forde, J.E. and Dale, T.C. 2007. Glycogen synthase kinase 3: A key regulator of cellular fate. Cell. Mol. Life Sci. 64: 19301944.

Hardy, C.F. and Pautz, A. 1996. A novel role for Cdc5p in DNA replication. Mol. Cell. Biol. 16: 6774-6782.

Hardy, C.F., Dryga, O., Seematter, S., Pahl, P.M., and Sclafani, R.A. 1997. $\mathrm{mcm} 5 / \mathrm{cdc} 46-b o b 1$ bypasses the requirement for the S phase activator Cdc7p. Proc. Natl. Acad. Sci. 94: 3151- 
3155.

Henderson, K.A., Kee, K., Maleki, S., Santini, P., and Keeney, S. 2006. Cyclin-dependent kinase directly regulates initiation of meiotic recombination. Cell 125: 1321-1332.

Hochwagen, A. and Amon, A. 2006. Checking your breaks: Surveillance mechanisms of meiotic recombination. Curr. Biol. 16: R217-R228. doi: 10.1016/j.cub.2006.03.009.

Hochwagen, A., Tham, W.H., Brar, G.A., and Amon, A. 2005. The FK506 binding protein Fpr3 counteracts protein phosphatase 1 to maintain meiotic recombination checkpoint activity. Cell 122: 861-873.

Hollingsworth Jr., R.E. and Sclafani, R.A. 1993. Yeast premeiotic DNA replication utilizes mitotic origin ARS1 independently of CDC7 function. Chromosoma 102: 415420.

Hovland, P., Flick, J., Johnston, M., and Sclafani, R.A. 1989. Galactose as a gratuitous inducer of $G A L$ gene expression in yeast growing on glucose. Gene 83: 57-64.

Jiao, K., Salem, L., and Malone, R. 2003. Support for a meiotic recombination initiation complex: Interactions among Rec102p, Rec104p and Spollp. Mol. Cell. Biol. 23: 59285938.

Keeney, S. 2001. Mechanism and control of meiotic recombination initiation. Curr. Top. Dev. Biol. 52: 1-53.

Kitada, K., Johnson, A.L., Johnston, L.H., and Sugino, A. 1993. A multicopy suppressor gene of the Saccharomyces cerevisiae G1 cell cycle mutant gene $d b f 4$ encodes a protein kinase and is identified as CDC5. Mol. Cell. Biol. 13: 44454457.

Kockeritz, L., Doble, B., Patel, S., and Woodgett, J.R. 2006. Glycogen synthase kinase-3-An overview of an over-achieving protein kinase. Curr. Drug Targets 7: 1377-1388.

Li, J., Hooker, G.W., and Roeder, G.S. 2006. Saccharomyces cerevisiae Mer2, Mei4 and Rec114 form a complex required for meiotic double-strand break formation. Genetics 173: 1969-1981.

Maleki, S., Neale, M.J., Arora, C., Henderson, K.A., and Keeney, S. 2007. Interactions between Mei4, Rec114, and other proteins required for meiotic DNA double-strand break formation in Saccharomyces cerevisiae. Chromosoma 116: 471486.

Masai, H. and Arai, K. 2002. Cdc7 kinase complex: A key regulator in the initiation of DNA replication. J. Cell. Physiol. 190: $287-296$.

Masai, H., Matsui, E., You, Z., Ishimi, Y., Tamai, K., and Arai, K. 2000. Human Cdc7-related kinase complex. In vitro phosphorylation of MCM by concerted actions of Cdks and Cdc7 and that of a criticial threonine residue of Cdc7 by Cdks. J. Biol. Chem. 275: 29042-29052.

Masai, H., Taniyama, C., Ogino, K., Matsui, E., Kakusho, N., Matsumoto, S., Kim, J.M., Ishii, A., Tanaka, T., Kobayashi, T., et al. 2006. Phosphorylation of MCM4 by Cdc7 kinase facilitates its interaction with $\mathrm{Cdc} 45$ on the chromatin. $J$. Biol. Chem. 281: 39249-39261.

McKee, A.H.Z. and Kleckner, N. 1997. A general method for identifying recessive diploid-specific mutations in Saccharomyces cerevisiae, its application to the isolation of mutants blocked at intermediate stages of meiotic prophase and characterization of a new gene SAE2. Genetics 146: 797816.

Montagnoli, A., Valsasina, B., Brotherton, D., Troiani, S., Rainoldi, S., Tenca, P., Molinari, A., and Santocanale, C. 2006. Identification of $\mathrm{Mcm} 2$ phosphorylation sites by S-phase-regulating kinases. I. Biol. Chem. 281: 1028110290.

Murakami, H. and Nurse, P. 2001. Regulation of premeiotic
$S$ phase and recombination-related double-strand DNA breaks during meiosis in fission yeast. Nat. Genet. 28: 290293.

Neiman, A.M. and Herskowitz, I. 1994. Reconstitution of a yeast protein kinase cascade in vitro: Activation of the yeast MEK homolog STE7 by STE11. Proc. Natl. Acad. Sci. 91: 3398-3402.

Niu, H., Wan, L., Baumgartner, B., Schaefer, D., Loidl, J., and Hollingsworth, N.M. 2005. Partner choice during meiosis is regulated by Hop1-promoted dimerization of Mek1. Mol. Biol. Cell 16: 5804-5818.

Nougarede, R., Della Seta, F., Zarzov, P., and Schwob, E. 2000. Hierarchy of S-phase-promoting factors: Yeast Dbf4-Cdc7 kinase requires prior S-phase cyclin-dependent kinase activation. Mol. Cell. Biol. 20: 3795-3806.

Pecina, A., Smith, K.N., Mezard, C., Murakami, H., Otha, K., and Nicolas, A. 2002. Target stimulation of meiotic recombination. Cell 111: 173-184.

Petes, T.D. 2001. Meiotic recombination hot spots and cold spots. Nat. Rev. Genet. 2: 360-369.

Petronczki, M., Siomos, M.F., and Nasmyth, K. 2003. Un menage a quatre: The molecular biology of chromosome segregation in meiosis. Cell 112: 423-440.

Prinz, S., Amon, A., and Klein, F. 1997. Isolation of COM1, a new gene required to complete meiotic double-strand induced recombination in Saccharomyces cerevisiae. Genetics 146: 781-795.

Sasanuma, H., Hirota, K., Fukuda, T., Kakusho, N., Kugou, K., Kawasaki, Y., Shibata, T., Masai, H., and Ohta, K. 2008. Cdc7-dependent phosphorylation of Mer2 facilitates initiation of yeast meiotic recombination. Genes \& Dev. (this issue), doi: 10.1101/gad.1626608.

Schild, D. and Byers, B. 1978. Meiotic effects of DNA-defective cell division cycle mutations of Saccharomyces cerevisiae. Chromosoma 70: 109-130.

Schwacha, A. and Kleckner, N. 1997. Interhomolog bias during meiotic recombination: Meiotic functions promote a highly differentiated interhomolog-only pathway. Cell 90: 11231135.

Sclafani, R.A. 2000. Cdc7p-Dbf4p becomes famous in the cell cycle. J. Cell Sci. 113: 2111-2117.

Shuster, E.O. and Byers, B. 1989. Pachytene arrest and other meiotic effects of the start mutations in Saccharomyces cerevisiae. Genetics 123: 29-43.

Smith, K.N., Penkner, A., Ohta, K., Klein, F., and Nicolas, A. 2001. B-type cyclins CLB5 and CLB6 control the initiation of recombination and synaptonemal complex formation in yeast meiosis. Curr. Biol. 11: 88-97.

Sopko, R., Raithatha, S., and Stuart, D. 2002. Phosphorylation and maximal activity of Saccharomyces cerevisiae meiosisspecific transcription factor $\mathrm{Ndt} 80$ is dependent on Ime2. Mol. Cell. Biol. 22: 7024-7040.

Strickfaden, S.C., Winters, M.J., Ben-Ari, G., Lamson, R.E., Tyers, M., and Pryciak, P.M. 2007. A mechanism for cellcycle regulation of MAP kinase signalling in a yeast differentiation pathway. Cell 128: 519-531.

Stuart, D. and Wittenberg, C. 1998. CLB5 and CLB6 are required for premeiotic DNA replication and activation of the meiotic S/M checkpoint. Genes \& Dev. 12: 2698-2710.

Tanaka, S., Umemori, T., Hirai, K., Muramatsu, S., Kamimura, Y., and Araki, H. 2007. CDK-dependent phosphorylation of Sld2 and Sld3 initiates DNA replication in budding yeast. Nature 445: 323-332.

Valentin, G., Schwob, E., and Della Seta, F. 2005. Dual role of the CDC7-regulatory protein DBF4 during yeast meiosis. I. Biol. Chem. 281: 2828-2834. 
Wan, L., de los Santos, T., Zhang, C., Shokat, K., and Hollingsworth, N.M. 2004. Mek1 kinase activity functions downstream of RED1 in the regulation of meiotic DSB repair in budding yeast. Mol. Biol. Cell 15: 11-23.

Wan, L., Zhang, C., Shokat, K.M., and Hollingsworth, N.M. 2006. Chemical inactivation of $\mathrm{Cdc} 7$ kinase in budding yeast results in a reversible arrest that allows efficient cell synchronization prior to meiotic recombination. Genetics 174: 1767-1774.

Wolfe, K.H. 2006. Comparative genomics and genome evolution in yeasts. Philos. Trans. R. Soc. Lond. B Biol. Sci. 361: 403-412.

Wu, T.C. and Lichten, M. 1994. Meiosis-induced double-strand break sites determined by yeast chromatin structure. Science 263: 515-518.

Zegerman, P. and Diffley, J.F. 2007. Phosphorylation of Sld2 and Sld3 by cyclin-dependent kinases promotes DNA replication in budding yeast. Nature 445: 281-285. 


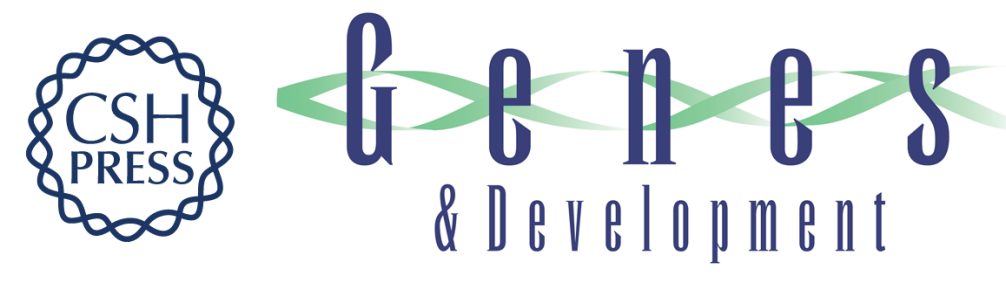

\section{Cdc28-Clb5 (CDK-S) and Cdc7-Dbf4 (DDK) collaborate to initiate meiotic recombination in yeast}

Lihong Wan, Hengyao Niu, Bruce Futcher, et al.

Genes Dev. 2008, 22:

Access the most recent version at doi:10.1101/gad.1626408

\section{Supplemental http://genesdev.cshlp.org/content/suppl/2008/01/16/22.3.386.DC1 \\ Material}

Related Content Regulating the formation of DNA double-strand breaks in meiosis

Hajime Murakami and Scott Keeney

Genes Dev. February , 2008 22: 286-292 Cdc7-dependent phosphorylation of Mer2

facilitates initiation of yeast meiotic recombination

Hiroyuki Sasanuma, Kouji Hirota, Tomoyuki Fukuda, et al.

Genes Dev. February , 2008 22: 398-410

References This article cites 55 articles, 25 of which can be accessed free at:

http://genesdev.cshlp.org/content/22/3/386.full.html\#ref-list-1

Articles cited in:

http://genesdev.cshlp.org/content/22/3/386.full.html\#related-urls

License

Email Alerting
Service $\begin{aligned} & \text { Receive free email alerts when new articles cite this article - sign up in the box at the top } \\ & \text { right corner of the article or click here. }\end{aligned}$

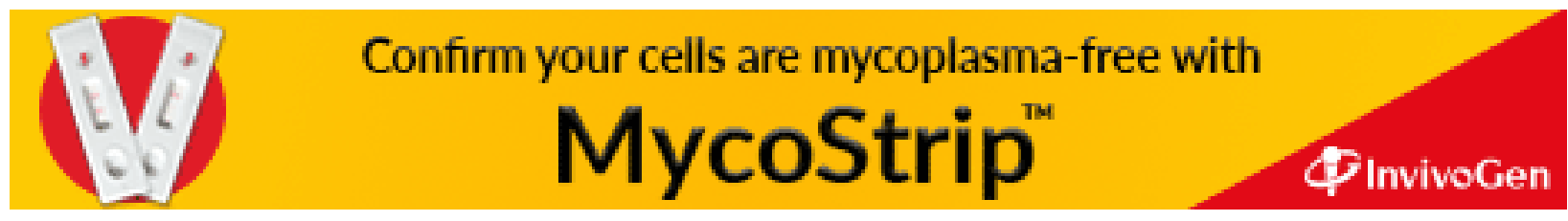

